\title{
Water solubility in orthopyroxene: Dependence on temperature and Al content
}

\author{
ZHANG BaoHua ${ }^{1,2^{*}}$, MATSUZAKI Takuya $^{1} \&$ WU XiaoPing ${ }^{2 *}$ \\ ${ }^{1}$ Institute for Study of the Earth's Interior, Okayama University, Misasa, Tottori-ken 682-0193, Japan; \\ ${ }^{2}$ School of Earth and Space Science, University of Science and Technology of China, Hefei 230026, China
}

Received October 16, 2012; accepted December 19, 2012; published online June 24, 2013

\begin{abstract}
The water solubility in $\mathrm{Al}-\mathrm{Fe}-\mathrm{Mg}$ orthopyroxene $\left[(\mathrm{Mg}, \mathrm{Fe}, \mathrm{Al})(\mathrm{Si}, \mathrm{Al}) \mathrm{O}_{3}: X_{\mathrm{Fe}}=0.1\right]$ was investigated as a function of temperature and $\mathrm{Al}$ contents. Experiments were performed at $10 \mathrm{kbar}$ with temperatures ranging from 800 to $1200^{\circ} \mathrm{C}$ under water-saturated conditions. Water contents in the $(\mathrm{Mg}, \mathrm{Fe}) \mathrm{SiO}_{3}-\mathrm{H}_{2} \mathrm{O}-\mathrm{Al}_{2} \mathrm{O}_{3}$ system were determined using unpolarized Fourier transform infrared spectroscopy. The present results show that water solubility in Al-bearing orthopyroxene decreases systematically with temperature from approximately 1 weight $\%$ at $800^{\circ} \mathrm{C}$ to $568 \pm 58 \mathrm{ppm}$ at $1200^{\circ} \mathrm{C}$ and increase significantly with increasing $\mathrm{Al}_{2} \mathrm{O}_{3}$ contents under the same annealing temperature and pressure. Combined with published results on the dependence of hydroxyl solubility on water fugacity and pressure, the present results can be described by the relation $C_{\mathrm{OH}}=A(T) f_{\mathrm{H}_{2} \mathrm{O}}^{n=0.5} \exp$ $\left(-\frac{\Delta H^{1 \text { bar }}+\Delta V^{\text {solid }} P}{\mathrm{R} T}\right)$, where $A=0.0024 \pm 0.0015 \mathrm{ppm} / \mathrm{bar}^{0.5}, \Delta H^{1 \text { bar }}=-103.348 \pm 9.768 \mathrm{~kJ} / \mathrm{mol}$, and $\Delta V^{\text {solid }}=9.2 \pm 1.1$ $\mathrm{cm}^{3} / \mathrm{mol}$. This equation implies that the incorporation mechanism of water in aluminous orthopyroxene involves the isolated $\mathrm{OH}$ groups. Based on the experimentally established solubility model used in this study, it is suggested that water solubility decreases with increasing temperature under typical upper mantle pressure. The predicted temperature dependence of water solubility is in good agreement with the previous experimental observations in Al-bearing orthopyroxene, but the opposite dependence is observed in Al-free systems. Moreover, our estimation of the water solubility in upper-mantle minerals as a function of depth for a typical oceanic geotherm might be of potential importance in interpreting the geophysical observations.
\end{abstract}

orthopyroxene, water solubility, infrared spectroscopy, asthenosphere

Citation: Zhang B H, Matsuzaki T, Wu X P. Water solubility in orthopyroxene: Dependence on temperature and Al content. Chin Sci Bull, 2013, 58: 3895-3902, doi: 10.1007/s11434-013-5953-5

The presence of water or hydroxyl defects in nominally anhydrous minerals (NAMs) has a dramatical influence on their geophysical properties such as solidus temperature [1], electrical conductivity [2-6] and viscosity [7-9], as well as on mantle dynamics such as melt generation [10] and mantle convection [7]. Critical to understanding the role of water in the Earth's mantle, a key step is to estimate the distribution of water inside the mantle and the incorporation mechanism of hydrogen in mantle minerals by combining experimentally determined mineral properties with geo-

*Corresponding authors (email: zhangbh@cc.okayama-u.ac.jp; wxp@ustc.edu.cn) physical observations. Two principal approaches can provide significant constraints on the water content in the Earth's interior. One approach is water solubility experiments in mantle minerals [11-13], and the other infers the water content based on the electrical conductivity of the NAMs [2-6,14-19].

Orthopyroxene is considered to be one of the main constituent minerals in the Earth's upper mantle and is believed to constitute approximately 20-40 vol\% [20]. Previous studies indicate that the water solubility in pure $\mathrm{MgSiO}_{3}$ enstatite increases with increasing pressure and temperature [21,22], while behavior of water solubility in Al-free ensta- 
tite is comparable to that in olivine $[11,23]$. In contrast, the incorporation of aluminum in orthopyroxene greatly increases the water solubility relative to that in the pure Al-free system [13,21,24-26]. As a result, the partition coefficient of water between aluminous enstatite and olivine is very high: $D_{\mathrm{H}_{2} \mathrm{O}}^{\mathrm{Opx} / \mathrm{Ol}}=11.7-25[13,27-30]$. Thus, the water content in the aluminous enstatite reaches values close to 1 wt.\% at low pressures and temperatures. Therefore, aluminous enstatite could be a more important host than olivine for water in the Earth's upper mantle, and it may be related to abnormal geophysical observations at the top of the asthenosphere $[1,3,7,13,16]$.

The solubility of water as a function of temperature and pressure has been investigated to determine the mechanism and thermodynamics of the incorporation of water in orthopyroxene [13,21,24,25,27-29]. However, it is worth noting that most studies were conducted using a pure $\mathrm{MgSiO}_{3}$ system [21,24,27-29] and single crystals of orthopyroxene. Except for two studies [13,25], few data on water solubility have been systematically reported for the $(\mathrm{Mg}$, $\mathrm{Fe}) \mathrm{SiO}_{3}-\mathrm{H}_{2} \mathrm{O}-\mathrm{Al}_{2} \mathrm{O}_{3}$ system (Al-Fe-Mg orthopyroxene) that simultaneously consider the influences of temperature and $\mathrm{Al}$ content. Additionally, the influence of $\mathrm{Al}$ content on water solubility and the substitution mechanism of hydrogen in orthopyroxene are not well understood. In this study, we report experimental results on the solubility of water (hydrogen) in Fe-bearing aluminous orthopyroxene aggregates as a function of temperature and $\mathrm{Al}$ content for polycrystal samples that were hydrothermally annealed under water-saturated conditions. Such information is critical in evaluating the role of water in orthopyroxene and for constructing the water storage capacity profile of the upper mantle.

\section{Experimental procedures}

Three different types of starting materials were used to synthesize the hydrogen-doped orthopyroxene; these starting materials had essentially the same $\mathrm{Mg}$ numbers [100* $\mathrm{Mg}$ / $(\mathrm{Mg}+\mathrm{Fe})=90]$ and $\mathrm{Al}_{2} \mathrm{O}_{3}$ contents $(3,6$ and $10 \mathrm{wt} . \%)$.

Aluminous enstatite starting materials with three different $\mathrm{Al}$ contents were prepared from a mixture of $\mathrm{MgO}$, $\mathrm{Fe}_{2} \mathrm{O}_{3}, \mathrm{SiO}_{2}$ and $\mathrm{Al}_{2} \mathrm{O}_{3}$ oxides using the following procedure. The oxide powders were dried at $1000^{\circ} \mathrm{C}$ for $4 \mathrm{~h}$ prior to weighing, and then, they were mixed and ground in an agate mortar for $2 \mathrm{~h}$. The glasses were synthesized from these mixtures by melting the mixtures under ambient pressure at $1600^{\circ} \mathrm{C}$ in air and quenching them in water. The resulting glasses were finely ground and pressed into pellets. The pellets were heated in an atmospheric-pressure furnace at $1200^{\circ} \mathrm{C}$ for one hour with a controlled oxygen partial pressure of $\log f \mathrm{O}_{2}=-8.47$ [log atm], which is close to the QFM buffer using a $\mathrm{CO}_{2}: \mathrm{H}_{2}$ gas mixture at a ratio of $19: 1$; the pellets were then quenched in water.

Sintered aluminous enstatite samples were synthesized in an end-loaded piston-cylinder apparatus at $1 \mathrm{GPa}$ and $800-1200^{\circ} \mathrm{C}$ using 3/4" pressure assemblies made of talc, Pyrex glass, graphite and crushable alumina for durations of up to $184 \mathrm{~h}$. A tapered graphite heater was used to reduce thermal gradients in the sample. Temperatures were measured using an S-type $\left(\mathrm{Pt}-\mathrm{PtRh} \mathrm{R}_{10}\right)$ thermocouple. For the hydrogen-doped (wet) aluminous enstatite sample, a mixture of starting materials and brucite powder as a water source (approximately $1 \mathrm{wt} \% \mathrm{H}_{2} \mathrm{O}$ ) was loaded into a Mo capsule. Then, the Mo capsule was inserted into a slightly larger Pt tube with an outer diameter of $3.0 \mathrm{~mm}$ and a wall thickness of $0.1 \mathrm{~mm}$; the tube was then sealed by welding. The platinum capsule was surrounded by sintered $\mathrm{MgO}$, which acted as an insulator from the graphite furnace. In several experiments, the enstatite powder was directly loaded into a Mo capsule without mixing it with $\mathrm{Mg}(\mathrm{OH})_{2}$ powder. The water content in the enstatite was controlled by changing the annealing conditions [13,22] (Table 1). Finally, the samples were cooled to room temperature at a cooling rate of approximately $100^{\circ} \mathrm{C} / \mathrm{min}$, which allowed us to obtain sintered enstatite without cracking due to thermal shock.

After the annealing experiments, the sintered enstatite aggregate was cut into halves using a diamond saw; one of the halves was doubly polished to a thin section of less than $0.1 \mathrm{~mm}$ thickness. The thin section was used for phase identification by micro-focused X-ray diffraction. The major elemental compositions were determined using an electron probe microanalyzer (JEOL JXA-8800) operated at an accelerating voltage of $15 \mathrm{kV}$ and a beam current of $12 \mathrm{nA}$. Three representative chemical compositions of the synthetic orthopyroxene are given in Table 2. The Mg numbers [Mg\# $=100 * \mathrm{Mg} /(\mathrm{Mg}+\mathrm{Fe})]$ in the hydrogen-doped aluminous enstatite samples with brucite are slightly higher than those in the samples without brucite (Table 2). The Al concentrations and $\mathrm{Mg \#}$ in the aluminous enstatite are very close to those in the initial glass starting materials (Table 1). The sample textures were examined by scanning electron microscopy, and the grain sizes were less than $20 \mu \mathrm{m}$.

After polishing and prior to Fourier Transform Infrared Spectroscopy (FT-IR) analysis, the samples were dried overnight at $200^{\circ} \mathrm{C}$ in a vacuum furnace to remove both grain boundary water and adsorbed water from the surface of the sample without releasing structurally bound $\mathrm{H}$. The water content of the Al-bearing enstatite was determined by FT-IR spectroscopy (Jasco Janssen MFT-2000) with unpolarized light. Measurements were performed using a nichrome light source, a Ge-coated $\mathrm{KBr}$ beam splitter, and a mercury-cadmium-telluride (MCT) detector. During the measurements, the beam path was continuously purged with dry $\mathrm{N}_{2}$. The IR beam was passed through a crack-free region of a $\sim 100 \times 100 \mu \mathrm{m}$ doubly polished sample spot, and several hundred to several thousand scans were accumulated for each analysis with $4 \mathrm{~cm}^{-1}$ resolution. For each sample, 
Table 1 Experimental results of water solubility in aluminous $\left[(\mathrm{Mg}, \mathrm{Fe}, \mathrm{Al})(\mathrm{Si}, \mathrm{Al}) \mathrm{O}_{3}: X_{\mathrm{Fe}}=0.1\right]$ orthopyroxene

\begin{tabular}{|c|c|c|c|c|c|c|}
\hline \multirow{2}{*}{ Sample } & \multirow{2}{*}{$P$ (kbar) } & \multirow{2}{*}{$T\left({ }^{\circ} \mathrm{C}\right)$} & \multirow{2}{*}{ Duration (h) } & \multicolumn{2}{|c|}{ Water content $\left(\mathrm{ppm}\right.$ wt $\left.\mathrm{H}_{2} \mathrm{O}\right)$} & \multirow{2}{*}{$\mathrm{Al}_{2} \mathrm{O}_{3}$ content (wt $\%$ ) } \\
\hline & & & & Paterson $^{\text {a) }}$ & Bell et al. ${ }^{\text {b) }}$ & \\
\hline En309 & 10 & 800 & 12 & $7480 \pm 268$ & $9285 \pm 930$ & $5.96 \pm 0.61$ \\
\hline En310 & 10 & 800 & 12 & $7060 \pm 512$ & $8862 \pm 1230$ & $3.12 \pm 0.96$ \\
\hline En307 & 10 & 850 & 18 & $8707 \pm 713$ & $10230 \pm 1027$ & $6.08 \pm 0.44$ \\
\hline En308 & 10 & 850 & 18 & $6406 \pm 168$ & $9343 \pm 3471$ & $3.14 \pm 0.16$ \\
\hline En306 & 10 & 900 & 10 & $7039 \pm 142$ & $9566 \pm 175$ & $3.56 \pm 1.24$ \\
\hline En131 & 10 & 900 & 184 & $7233 \pm 537$ & $9324 \pm 687$ & $6.40 \pm 0.38$ \\
\hline En127 & 10 & 900 & 20 & $2411 \pm 186$ & $4016 \pm 255$ & $9.42 \pm 0.19$ \\
\hline En $126^{\mathrm{c})}$ & 10 & 900 & 20 & $1156 \pm 144$ & $1687 \pm 124$ & $9.88 \pm 0.15$ \\
\hline En $120^{\text {c) }}$ & 10 & 1000 & 2 & $791 \pm 152$ & $1114 \pm 129$ & $3.47 \pm 0.24$ \\
\hline En208 & 10 & 1000 & 8 & $4441 \pm 185$ & $4667 \pm 178$ & $10.20 \pm 0.33$ \\
\hline En $129^{c)}$ & 10 & 1100 & 24 & $562 \pm 65$ & $596 \pm 55$ & $3.27 \pm 0.29$ \\
\hline En $130^{\mathrm{c})}$ & 10 & 1100 & 24 & $570 \pm 171$ & $678 \pm 45$ & $6.56 \pm 0.38$ \\
\hline En $121^{\mathrm{c})}$ & 10 & 1200 & 3 & $517 \pm 60$ & $568 \pm 58$ & $3.04 \pm 0.77$ \\
\hline En122 ${ }^{\mathrm{c}}$ & 10 & 1200 & 3 & $526 \pm 54$ & $583 \pm 39$ & $6.11 \pm 0.38$ \\
\hline
\end{tabular}

a) Calibration of Paterson [31]; b) calibration of Bell et al. [32]; c) synthesized without brucite powder.

Table 2 Representative chemical composition of the synthetic orthopyroxene determined using an electron microprobe

\begin{tabular}{cccccccc}
\hline Sample & $\mathrm{SiO}_{2}(\mathrm{wt} \%)$ & $\mathrm{MgO}(\mathrm{wt} \%)$ & $\mathrm{FeO}^{* \mathrm{a})}(\mathrm{wt} \%)$ & $\mathrm{Al}_{2} \mathrm{O}_{3}(\mathrm{wt} \%)$ & $\mathrm{CaO}(\mathrm{wt} \%)$ & $\mathrm{Total}(\mathrm{wt} \%)$ & $\mathrm{Mg} \#^{\mathrm{b})}$ \\
\hline Opx A & 56.20 & 34.33 & 6.35 & 3.04 & 0.23 & 100.15 & 90.3 \\
Opx B & 52.91 & 33.68 & 6.26 & 6.11 & 0.21 & 99.17 & 90.7 \\
Opx C & 51.47 & 31.38 & 6.10 & 9.88 & 0.27 & 99.10 & 90.2 \\
\hline
\end{tabular}

a) $\mathrm{FeO} *$ total $\mathrm{Fe}$ as $\mathrm{FeO}$; b) $\mathrm{Mg} \#=100 * \mathrm{Mg} /(\mathrm{Mg}+\mathrm{Fe})$.

at least 5 measurements were taken in different areas.

The water content of the aluminous orthopyroxene samples was determined by FT-IR spectra using both the frequency-dependent calibration of extinction coefficients reported by Paterson [31] and the independently calibrated extinction coefficients of orthopyroxene reported by Bell et al. [32]. It is well known that Paterson's [31] calibration was based on an empirical correlation between the $\mathrm{OH}-$ stretching frequency and the extinction coefficient in different glasses and quartz; this correlation is likely matrix-dependent. However, Bell et al. [32] found that the concentration of $\mathrm{H}_{2} \mathrm{O}$ for most NAMs may be underestimated by the method proposed by Paterson [31]. In our experiment, the integral molar absorption coefficient of $I=$ $80600 \pm 3200\left[\mathrm{~L} /\left(\mathrm{mol} \cdot \mathrm{cm}^{2}\right)\right][32]$ was used to calculate the water content in orthopyroxene directly. In previous studies, few researchers considered the $\mathrm{Al}_{2} \mathrm{O}_{3}$ content dependence of density in orthopyroxene during the calculation of water content. Clearly, arbitrarily assuming a constant density will result in large uncertainties in determining the water content. Based on the solubility of $\mathrm{Al}_{2} \mathrm{O}_{3}$ in $(\mathrm{Fe}, \mathrm{Mg}) \mathrm{SiO}_{3}$ orthopyroxene [33,34], an approximate relation was proposed to estimate the density of $\left[(\mathrm{Mg}, \mathrm{Fe}, \mathrm{Al})(\mathrm{Si}, \mathrm{Al}) \mathrm{O}_{3}: X_{\mathrm{Fe}}=0.1\right]$ orthopyroxene:

$$
d=3.2823+0.004 \times C_{\mathrm{Al}_{2} \mathrm{O}_{3}},
$$

where $d$ is density in $\mathrm{g} / \mathrm{cm}^{3}, C_{\mathrm{Al}_{2} \mathrm{O}_{3}}$ is the concentration of $\mathrm{Al}_{2} \mathrm{O}_{3}$ in wt\%. In this calculation, an orientation factor of
$1 / 3$ [31] was used, and the $\mathrm{OH}$ concentrations were determined from averages of several unpolarized measurements on randomly oriented grains of orthopyroxene samples using both the calibration of Paterson [31] and the weighted correction method of Bell et al. [32] with integration limits of 2950 to $3780 \mathrm{~cm}^{-1}$. Additionally, it has been claimed that the Paterson calibration for unpolarized FT-IR spectra may underestimate the water content in nominally anhydrous minerals (especially olivine) by a factor of 3 [35] compared to the calibration of Bell et al. [36]. Because the FT-IR measurements were performed using a polycrystalline sample, the single crystal calibration method [36] is not applicable to our samples, and the error of the water content calculated from the spectra obtained from randomly oriented crystals would be smaller.

\section{Results}

Representative FT-IR spectra of hydrogen-doped aluminous orthopyroxene are shown in Figure 1. The infrared spectra of aluminous enstatite aggregates display a strong absorption band at approximately $3580-3590 \mathrm{~cm}^{-1}$ and weak absorption at approximately $3500-3520 \mathrm{~cm}^{-1}$, irrespective of the water content. These features and peak positions are similar to those reported by Mierdel et al. [13] and are confirmed by the new in-situ observations of the natural orthopyroxene sample [37]. Interestingly, a notable absorption 


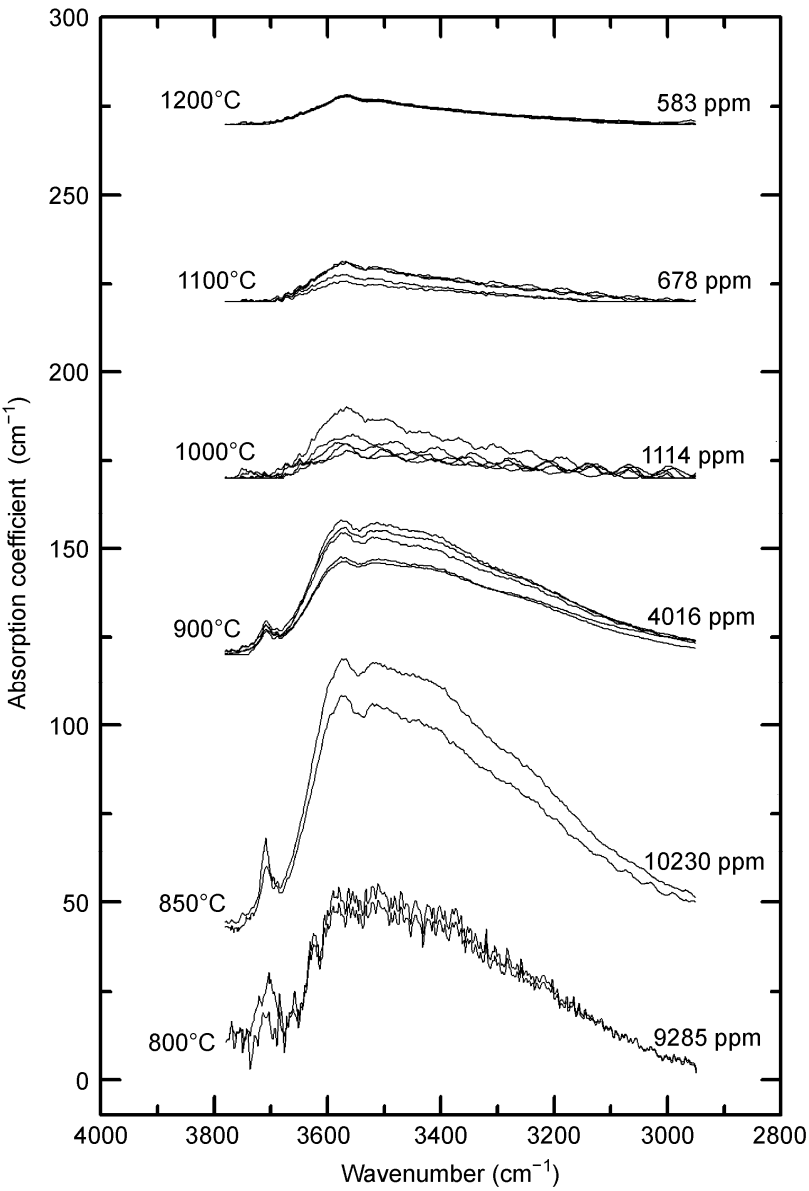

Figure 1 Unpolarized FT-IR spectra of synthetic $(\mathrm{Mg}, \mathrm{Fe}, \mathrm{Al})(\mathrm{Si}, \mathrm{Al}) \mathrm{O}_{3}$ orthopyroxene at a pressure of $10 \mathrm{kbar}$ and a temperature of $800-1200^{\circ} \mathrm{C}$.

band occurs at $3708 \mathrm{~cm}^{-1}$ at low temperature; as the temperature increases, the intensity of the peak at $3708 \mathrm{~cm}^{-1}$ gradually decreases and disappears at temperatures greater than $1000^{\circ} \mathrm{C}$. A possible explanation for this band might be a slight modification in the orthopyroxene structure or altered aluminum content [22].

Experimental data on water solubility in aluminous Fe-bearing orthopyroxene (Al-Fe-Mg orthopyroxene) at 10 kbar are summarized in Table 1. Obviously, water solubility decreases significantly as the temperature increases and ranges from approximately $1 \mathrm{wt} \%$ at $800^{\circ} \mathrm{C}$ to $568 \pm 58$ $\mathrm{ppm}$ at $1200^{\circ} \mathrm{C}$. This behavior is opposite to that observed in Al-free enstatite [22] and olivine [11,23]. However, we noted that the Paterson [31] calibration yields lower absolute values than those derived from the extinction coefficients of Bell et al. [32].

\section{Discussion}

\subsection{Effects of temperature and Al content}

A series of experiments were conducted to investigate the effect of temperature on the water solubility in Al-bearing orthopyroxene. As illustrated in Figure 2, the water solubility

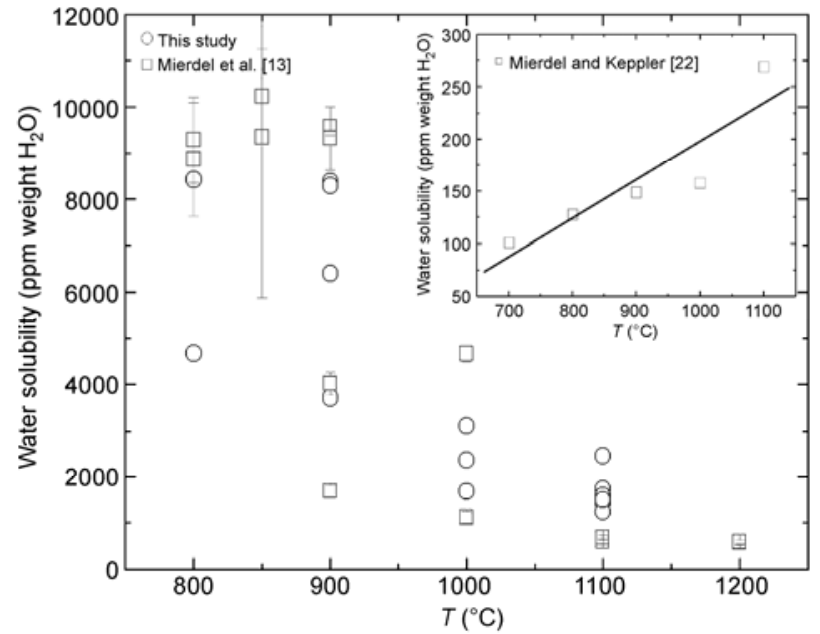

Figure 2 Water solubility (in ppm weight $\mathrm{H}_{2} \mathrm{O}$ ) in aluminous orthopyroxene as a function of temperature. The inset graph is the solubility of water in pure enstatite under water-saturated conditions at $15 \mathrm{kbar}$ and $700-1100^{\circ} \mathrm{C}[22]$.

of aluminous orthopyroxene shows a strongly negative temperature dependence. The systematic variations in water solubility with temperature observed in this study are comparable to the experimental results of Mierdel et al. [13], which show that water solubility decreases as temperature increases in synthetic orthopyroxene. In contrast, the water solubility in Al-free orthopyroxene increases with increasing temperature, as shown by Mierdel and Keppler [22] (see the inset graph in Figure 2). This trend is similar to that observed in olivine. Thus, the temperature dependence of water solubility is completely opposite for Al-bearing and $\mathrm{Al}$-free orthopyroxene. The main reason for this trend is that the thermodynamics of water solubility are primarily controlled by the type of $\mathrm{OH}$ defect that forms.

It is known that aluminum can greatly enhance water solubility in orthopyroxene $[12,13,21,26-30,38]$; thus, one crucial factor in determining the solubility of water in orthopyroxene is likely to be the concentration of aluminum. According to previous studies [24,38,39], the most likely substitution mechanism for $\mathrm{Al}$ incorporation in aluminous orthopyroxene is through the Tschermaks-substitution reaction: $\mathrm{Mg}^{2+}+\mathrm{Si}^{4+}=2 \mathrm{Al}^{3+}$. Nevertheless, hydrothermal annealing experiments have shown that most water is dissolved by the coupled substitution of $\mathrm{Al}^{3+}+\mathrm{H}^{+}$for $\mathrm{Si}^{4+}$ and by the substitution of $\mathrm{Al}^{3+}+\mathrm{H}^{+}$for $2 \mathrm{Mg}^{2+}[13,24,38,39]$. Both substitutions appear to occur with roughly equal abundance; consequently, Al is distributed approximately equally among tetrahedral and octahedral sites, irrespective of water content. In addition, Zhang et al. [19] recently measured the electrical conductivity of hydrous aluminous orthopyroxene; their data showed that the proton conduction of orthopyroxene strongly depended on the hydrogen concentration alone and is likely to be independent of $\mathrm{Al}$ content. These results indicate that the migration of interstitial 
protons is not accompanied by $\mathrm{Al}^{3+}$ migration and is much faster than that of $\mathrm{Al}^{3+}$ ions because of the extremely small ionic radius of protons. Additionally, our synthesized orthopyroxene aggregates may have initially had a small amount of defects (such as interstitial and vacancy sites), which could be occupied by hydrogen. If interstitial protons with fast diffusivity are a main charge carrier in orthopyroxene, such interstitial protons seem to be difficult to identify as a specific peak in the FT-IR spectra [19].

To further explore the possible relationship between water solubility and $\mathrm{Al}_{2} \mathrm{O}_{3}$ contents, Figure 3 displays the water solubility in orthopyroxene as a function of $\mathrm{Al}_{2} \mathrm{O}_{3}$ contents. As summarized in Table 1 and Figure 3 for the orthopyroxene samples with relatively low water contents, the water solubility of $(\mathrm{Mg}, \mathrm{Fe}, \mathrm{Al})(\mathrm{Si}, \mathrm{Al}) \mathrm{O}_{3}$ orthopyroxene increases with increasing $\mathrm{Al}_{2} \mathrm{O}_{3}$ contents under the same annealing temperature and pressure. This positive correlation between the $\mathrm{H}_{2} \mathrm{O}$ and $\mathrm{Al}_{2} \mathrm{O}_{3}$ contents is consistent with the previous experimental results of Rauch and Keppler [21] and Stalder [38] in synthetic enstatite but is contrary to the observations of Mierdel et al. [13]. However, in the case of orthopyroxene samples with higher water contents, the water solubility displays unexpected variation among $(\mathrm{Mg}, \mathrm{Fe}$, $\mathrm{Al})(\mathrm{Si}, \mathrm{Al}) \mathrm{O}_{3}$ orthopyroxenes synthesized at the same conditions. For example, even at the same pressure and temperature $\left(10 \mathrm{kbar}\right.$ and $\left.900^{\circ} \mathrm{C}\right)$, the water content in one orthopyroxene sample (En126; its $\mathrm{Al}_{2} \mathrm{O}_{3}$ content is $3.56 \mathrm{wt} \%$ ) was six times higher than that of another sample (En306; its $\mathrm{Al}_{2} \mathrm{O}_{3}$ content is $9.88 \mathrm{wt} \%$ ). The cause of the variation in the water content might be the difference in the chemical environment. Although no obvious correlation between water and $\mathrm{Al}_{2} \mathrm{O}_{3}$ contents was found for the case of enstatite aggregates with higher water contents, the incorporation of $\mathrm{Al}$ can undoubtedly enhance the water solubility in orthopyroxene to a great extent. Nevertheless, it was not easy to precisely control the water content by adding variable amounts of

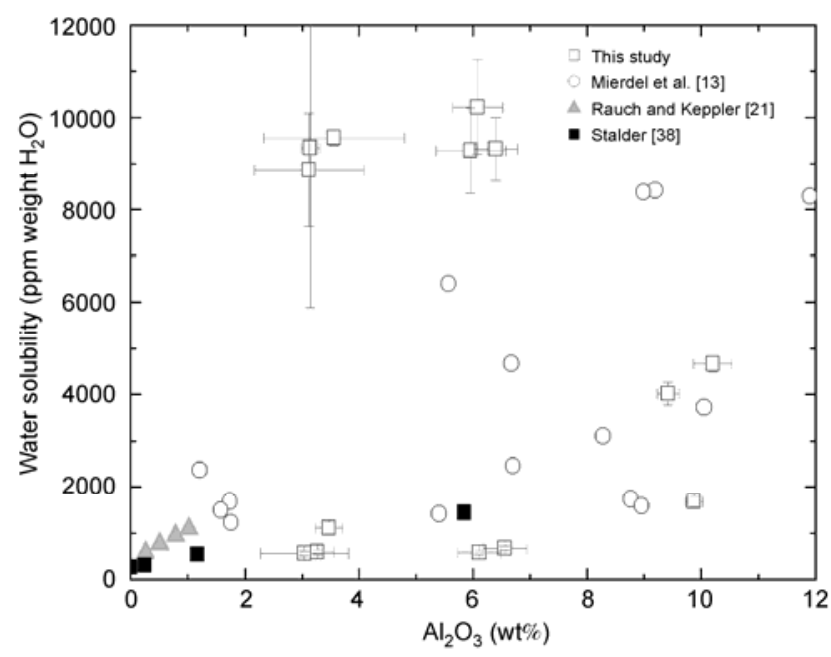

Figure $3 \quad \mathrm{Al}_{2} \mathrm{O}_{3}$ contents (wt $\%$ ) versus water solubility (in ppm weight $\mathrm{H}_{2} \mathrm{O}$ ) in aluminous orthopyroxene. brucite or Al. Based on our hydration experiments, if no brucite was added, the maximum water content was limited (for example, $0.168 \mathrm{wt} \%$ for En126). If brucite was added, the water content could reach $0.956 \mathrm{wt} \%$ under similar conditions. However, we could not obtain a clear systematic relationship between $\mathrm{H}_{2} \mathrm{O}$ and $\mathrm{Al}_{2} \mathrm{O}_{3}$ contents. Therefore, further studies are required to clarify the magnitude of the effect of $\mathrm{Al}$ on the water solubility in orthopyroxene.

\subsection{Thermodynamics of water solubility in orthopy- roxene}

Water solubility experiments as a function of temperature, pressure and composition provide a means of understanding the incorporation of $\mathrm{OH}$ in terms of point defects. It has been suggested that there are three different mechanisms of water solubility in NAMs [12,13,21,22,40]: (1) formation of isolated $\mathrm{OH}$ groups (water solubility should be proportional to the square root of water fugacity, $n=0.5$ ); (2) formation of $\mathrm{OH}$ pairs (water solubility should be proportional to water fugacity, $n=1)$; and (3) formation of $(\mathrm{OH})_{4}$ clusters (water solubility should be proportional to the square of water fugacity, $n=2$ ). In this study, we focus on the incorporation of $\mathrm{OH}$ in aluminous orthopyroxene. Based on the aforementioned discussion and previous studies [12,13,21, $26,38,39$ ], two substitution mechanisms (i.e. $\mathrm{Al}^{3+}+\mathrm{H}^{+}$for $\mathrm{Si}^{4+}$ and $\mathrm{Al}^{3+}+\mathrm{H}^{+}$for $2 \mathrm{Mg}^{2+}$ ) are the most likely to form the isolated $\mathrm{OH}$ groups in aluminous orthopyroxene. Therefore, the corresponding equilibrium can be described by the equation:

$$
\mathrm{H}_{2} \mathrm{O}_{\text {fluid }}+\mathrm{O}_{\text {mineral }}=2 \mathrm{OH}_{\text {mineral }}
$$

with the equilibrium constant

$$
K=\frac{a_{\mathrm{OH}}^{2}}{f_{\mathrm{H}_{2} \mathrm{O}} a_{\mathrm{O}}},
$$

where $a_{\mathrm{OH}}$ is the activity of $\mathrm{OH}$ in orthopyroxene, $f_{\mathrm{H}_{2} \mathrm{O}}$ is the water fugacity and $a_{\mathrm{O}}$ is the activity of unprotonated oxygens in orthopyroxene. As only a minute fraction of all oxygen atoms will be protonated, $a_{\mathrm{O}}$ can be assumed to be constant, and the activity of $\mathrm{OH}$ will be directly proportional to its concentration $\left(C_{\mathrm{OH}}\right)$. This implies that the concentration of $\mathrm{OH}$ should be proportional to the square root of the water fugacity:

$$
C_{\mathrm{OH}} \propto f_{\mathrm{H}_{2} \mathrm{O}}^{n=0.5}
$$

The equilibrium constant $K$ is related to the Gibbs free energy $\Delta G$ according to

$$
-R T \ln K=\Delta G=\Delta H^{1 \mathrm{bar}}-T \Delta S^{1 \mathrm{bar}}+\Delta V^{\mathrm{solid}}(P-1 \text { bar }),
$$

where $\Delta H^{1 \text { bar }}$ and $\Delta S^{\text {bar }}$ are the reaction enthalpy and entropy at 1 bar, respectively; $\Delta V^{\text {solid }}$ is the volume 
change of the solids during hydroxylation; $R$ is the gas constant; $T$ is temperature and $P$ is pressure. Additionally, in the term $(P-1$ bar), 1 bar can be neglected compared to the pressure considered. Because $\mathrm{H}$ or $\mathrm{OH}$ is a dilute species, it is generally assumed that the activity of the dissolved $\mathrm{OH}$ species is proportional to the concentration of dissolved water and that the activity of the unprotonated oxygen atoms remains essentially constant. By inserting eq. (3) into eq. (5), one obtains

$$
C_{\mathrm{OH}}\left(P, T, f_{\mathrm{H}_{2} \mathrm{O}}\right)=A(T) f_{\mathrm{H}_{2} \mathrm{O}}^{n=0.5} \exp \left(-\frac{\Delta H^{1 \text { bar }}+\Delta V^{\text {solid }} P}{\mathrm{R} T}\right) \text {, }
$$

where $C_{\mathrm{OH}}$ is water solubility in ppm by weight, and $A$ is a constant that is essentially related to the entropy of reaction.

Using water contents derived from the extinction coefficients by Bell et al. [32], a multiple regression fit of all the experimental data from this study together with all the data from Mierdel et al. [13] to eq. (6) yielded $A=0.0024 \pm$ $0.0015 \mathrm{ppm} / \mathrm{bar}^{0.5}, \Delta H^{1 \text { bar }}=-103.348 \pm 9.768 \mathrm{~kJ} / \mathrm{mol}$, and $\Delta V^{\text {solid }}=9.2 \pm 1.1 \mathrm{~cm}^{3} / \mathrm{mol}$. In this regression fit, water fugacities were calculated using the equation of state from Pitzer and Sterner [41]. A summary of the thermodynamic models for water solubility in orthopyroxene derived from the water solubility experiments is compiled in Table 3. Additionally, Figure 4 compares the predicted water contents in Al-bearing orthopyroxene as a function of temperature and pressure from the thermodynamic model of eq. (6) with the experimentally measured water contents from this study and previous work [13]. At typical upper mantle pressure, our thermodynamic model predicts decreasing water solubility with increasing temperature (Figure 4). This trend agrees with that predicted by Mierdel et al. [13] in Al-bearing orthopyroxene; however, the trend is contrary to that in Al-free enstatite predicted by Mierdel and Keppler [22].

\subsection{Geophysical implications}

To assess the presence and distribution of water in the upper mantle, we estimated the storage capacity of water as a function of depth by extrapolating the present experimental data to the upper mantle in terms of eq. (6) and the fitting parameters for aluminous enstatite aggregate (Table 3 ). The temperature distributions are largely controlled by the conductive heat transfer in the lithosphere. The geotherm was determined from thermobarometry of mantle xenoliths for the continental mantle [42] and was derived from surface heat flow for the oceanic mantle [43]. The geotherm in the deep regions of a typical oceanic upper mantle was considered to be adiabatic, which was taken from Katsura et al. [44]. In the shallow part of the upper mantle, the geotherms change from conductive to adiabatic at depths approximately $60 \mathrm{~km}$ for oceanic mantle $[9,15]$. Consequently, in this work, the temperature-depth profile for a typical oceanic upper mantle (assuming an age of $80 \mathrm{Ma}$ ) was obtained from Karato [9], whereas Mierdel et al. [13] considered a constant temperature gradient $(0.3 \mathrm{~K} / \mathrm{km}$ [43]). To evaluate the contribution of aluminous enstatite to the water storage capacity of the asthenosphere, the upper mantle was simplified to comprise $40 \mathrm{vol} \%$ of aluminous enstatite and 60 vol $\%$ of olivine. The water solubility of olivine was taken from Hirschmann et al. [45].

Figure 5 shows how the predicted water solubility in the oceanic upper mantle varies with the depth in the upper mantle. For Al-free orthopyroxene, the water solubility continuously increases with depth (also pressure and temperature), which is roughly comparable to the trend in olivine $[11,23]$. However, for Al-bearing orthopyroxene and the mixture model (40 vol\% opx +60 vol\% olivine), our predictions show that the water solubility in upper mantle minerals has a pronounced minimum corresponding to the depth of the low velocity zone. Comparing our model calculations to previously published results [13], we found that the variation was similar, but the minimum values of water solubility yielded in our calculations were $150 \mathrm{ppm}$ lower than those of Mierdel et al. [13]. This observation supports the idea that the origin of Earth's asthenosphere may be related to partial melting [13] because the sharp decrease in water solubility with depth and a lower minimum must release large amounts of water, and it is easier to form a hydrous melt in the asthenosphere.

Although our results show that Al-bearing orthopyroxene might contain enormous amounts of water compared to the olivine at the top of asthenosphere, the water content of Al-bearing orthopyroxene rapidly decreases due to the significant drop in the solubility. This decrease occurs because the maximum solubility of water is dependent on the pressure and $\mathrm{Al}$ content, and the $\mathrm{Al}$ content of enstatite rapidly decreases in this pressure range due to the stabilization of garnet. In addition, our recent experimental studies [3,15,19] have verified that neither hydrous aluminous enstatite nor

Table 3 Summary of the thermodynamic models for water solubility in orthopyroxene derived from water solubility experiments

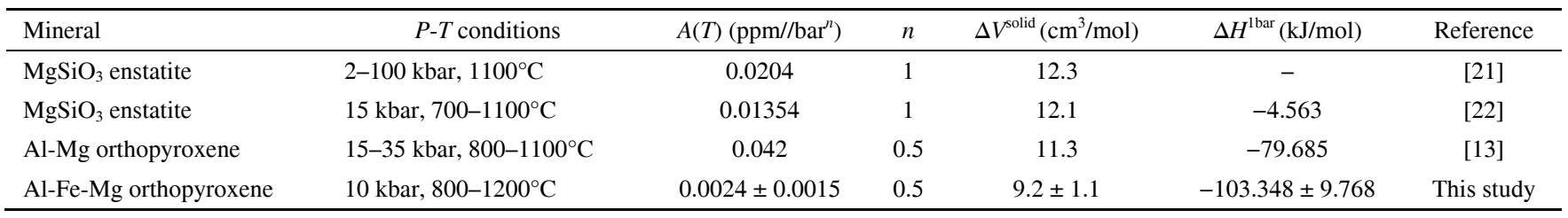




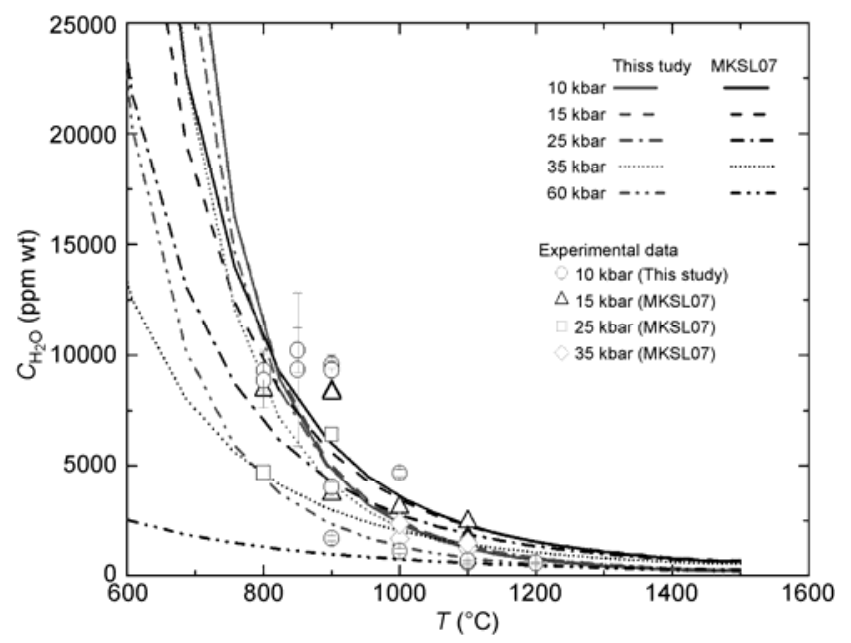

Figure 4 Predicted water solubility (in ppm weight $\mathrm{H}_{2} \mathrm{O}$ ) in Al-bearing orthopyroxene as a function of temperature and pressure according to the thermodynamic models of eq. (6) and MKSL07 [13].

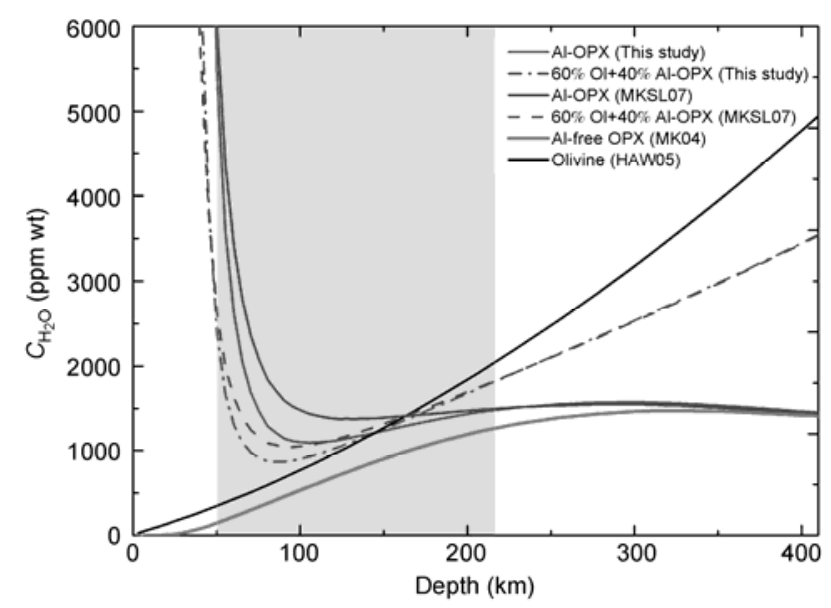

Figure 5 Water solubility (in ppm weight $\mathrm{H}_{2} \mathrm{O}$ ) in upper-mantle minerals as a function of depth for a typical oceanic geotherm [44]. Water solubility in Al-bearing and Al-free orthopyroxene according to MKSL07 [13] and MK04 [22], respectively. Water solubility in olivine from HAW05 [45]. The shaded area represents the typical position of the asthenosphere below oceans.

hydrous olivine can be used to explain the high anisotropy of conductivity observed at the top of the asthenosphere. Consequently, the most probable explanation for such geophysical observations could be the presence of a partial melt at the depth corresponding to the low velocity zone in the upper mantle [3,13]. However, few direct experimental studies have been published on this topic so far. Thus, additional studies are needed to verify the hypothesis of partial melting and to clarify the origin of Earth's asthenosphere.

We thank T. Katsura and T. Yoshino for stimulating discussions and constructive suggestions. The authors also thank the two anonymous reviewers for their constructive comments that improved the manuscript. The experimental work reported in this paper was performed while B.H. Zhang was a PhD candidate at USTC. This work was supported by the National Nat- ural Science Foundation of China (41074048), the National High-tech $R \& D$ Program of China (2012AA061403) and the COE-21 Program of ISEI, Okayama University.

1 Hirschmann M M, Tenner T, Aubaud C, et al. Dehydration melting of nominally anhydrous mantle: The primacy of partitioning. Phys Earth Planet Inter, 2009, 176: 54-68

2 Karato $\mathrm{S}$. The role of hydrogene in the electrical conductivity of the upper mantle. Nature, 1990, 347: 272-273

3 Yoshino T, Matsuzaki T, Yamashita S, et al. Hydrous olivine unable to account for conductivity anomaly at the top of the asthenosphere. Nature, 2006, 443: 973-976

4 Wang D J, Mookherjee M, Xu Y S, et al. The effect of water on the electrical conductivity in olivine. Nature, 2006, 443: 977-980

5 Wang D J, Li H P, Yi L, et al. The electrical conductivity of upper-mantle rocks: Water content in the upper mantle. Phys Chem Miner, 2008, 35: 157-162

6 Poe B T, Romano C, Nestola F, et al. Electrical conductivity anisotropy of dry and hydrous olivine at $8 \mathrm{GPa}$. Phys Earth Planet Inter, 2010, 181: 103-111

7 Hirth G, Kohlstedt D L. Water in the oceanic upper mantle: Implications for rheology, melt extraction and the evolution of the lithosphere. Earth Planet Sci Lett, 1996, 144: 93-108

8 Mei S, Kohlstedt D L. Influence of water on plastic deformation of olivine aggregates, part I: Diffusion creep regime. J Geophys Res, 2000, 105: 21457-21469

9 Karato S. Rheology of the deep upper mantle and its implications for the preservation of the continental roots: A review. Tectonophysics, 2010, 481: 82-98

10 Hirose K, Kawamoto T. Hydrous partial melting of lherzolite at 1 GPa: The effect of $\mathrm{H}_{2} \mathrm{O}$ on the genesis of basaltic magmas. Earth Planet Sci Lett, 1995, 133: 463-473

11 Kohlstedt D L, Keppler H, Rubie D C. The solubility of water in $\alpha, \beta$ and $\gamma$ phases of $(\mathrm{Mg}, \mathrm{Fe})_{2} \mathrm{SiO}_{4}$. Contrib Mineral Petrol, 1996, 123: 345-357

12 Keppler H, Bolfan-Casanova N. Thermodynamics of water solubility and partitioning. Rev Mineral Geochem, 2006, 62: 193-230

13 Mierdel K, Keppler H, Smyth J R, et al. Water solubility in aluminous orthopyroxene and the origin of Earth's asthenosphere. Science, 2007, 315: 364-368

14 Yoshino T, Manthilake G, Matsuzaki T, et al. Dry mantle transition zone inferred from the conductivity of wadsleyite and ringwoodite. Nature, 2008, 451: 326-329

15 Yoshino T, Matsuzaki T, Shatskiy A, et al. The effect of water on the electrical conductivity of olivine aggregates and its implications for the electrical structure of the upper mantle. Earth Planet Sci Lett, 2009, 288: 291-300

16 Dai L D, Karato S. Electrical conductivity of orthopyroxene: Implications for the water content of the asthenosphere. Proc Jpn Acad Ser B, 2009, 85: 466-475

17 Dai L D, Karato S. Electrical conductivity of wadsleyite under high pressures and temperatures. Earth Planet Sci Lett, 2009, 287: 277283

18 Zhang B H, Wu X P, Xu J S, et al. Electrical conductivity of enstatite up to $20 \mathrm{GPa}$ and $1600 \mathrm{~K}$. Chin J Geophys, 2010, 53: 760-764

19 Zhang B H, Yoshino T, Wu X P, et al. Electrical conductivity of enstatite as a function of water content: Implications for the electrical structure in the upper mantle. Earth Planet Sci Lett, 2012, doi: 10. 1016/j.epsl.2012.09.020

20 Ringwood A E. Composition and Petrology of the Earth's Mantle. New York: McGraw-Hill, 1975. 1-618

21 Rauch M, Keppler H. Water solubility in orthopyroxene. Contrib Mineral Petrol, 2002, 143: 525-536

22 Mierdel K, Keppler H. The temperature dependence of water solubility in enstatite. Contrib Mineral Petrol, 2004, 148: 305-311

23 Zhao Y H, Ginsberg S B, Kohlstedt D L. Solubility of hydrogen in olivine: dependence on temperature and iron content. Contrib Mineral Petrol, 2004, 147: 155-161 
24 Stalder R, Skogby H. Hydrogen incorporation in enstatite. Eur J Mineral, 2002, 14: 1139-1144

25 Stalder R, Klemme S, Ludwig T, et al. Hydrogen incorporation in orthopyroxene: Interaction of different trivalent cations. Contrib Mineral Petrol, 2005, 150: 473-485

26 Smyth J R, Mierdel K, Keppler H, et al. Crystal chemistry of hydration in aluminous orthopyroxene. Am Mineral, 2007, 92: 973-976

27 Hauri E H, Gaetani G A, Green T H. Partitioning of water during melting of the Earth's upper mantle at $\mathrm{H}_{2} \mathrm{O}$-undersaturated conditions. Earth Planet Sci Lett, 2006, 248: 715-734

28 Grant K J, Kohn S C, Brooker R A. Solubility and partitioning of water in synthetic forsterite and enstatite in the system $\mathrm{MgO}-\mathrm{SiO}_{2}-$ $\mathrm{H}_{2} \mathrm{O} \pm \mathrm{Al}_{2} \mathrm{O}_{3}$. Contrib Mineral Petrol, 2006, 151: 651-664

29 Grant K, Ingrin J, Lorand J P, et al. Water partitioning between mantle minerals from peridotite xenoliths. Contrib Mineral Petrol, 2007, 154: $15-34$

30 Tenner T, Hirschmann M M, Withers A C, et al. Hydrogen partitioning between nominally anhydrous upper mantle minerals and melt between 3 and $5 \mathrm{GPa}$ and applications to hydrous peridotite partial melting. Chem Geol, 2009, 262: 42-56

31 Paterson M S. The determination of hydroxyl by infrared absorption in quartz, silicate glasses and similar materials. Bull Minéral, 1982, 105: 20-29

32 Bell D R, Ihinger P D, Rossman G R. Quantitative analysis of trace $\mathrm{OH}$ in garnet and pyroxenes. Am Mineral, 1995, 80: 465-474

33 Ganguly J, Ghose S. Aluminous orthopyroxene: Order-disorder, thermodynamic properties, and petrologic implications. Contrib Mineral Petrol, 1979, 69: 375-385

34 Xie H S. Introduction to the Material Sciences of the Earth's Interior. Beijing: Science Press, 1997. 1-297

35 Mosenfelder J L, Deligne N I, Asimov P D, et al. Hydrogen incorpo- ration in olivine from 2-12 GPa. Am Mineral, 2006, 91: 285-294

36 Bell D R, Rossman G R, Maldener J, et al. Hydroxide in olivine: A quantitative determination of the absolute amount and calibration of the IR spectrum. J Geophys Res, 2003, 108: 2105

37 Yang Y, Xi Q K, Feng M, et al. OH in natural orthopyroxene: An in situ FTIR investigation at varying temperatures. Phys Chem Mineral, 2012, 39: 413-418

38 Stalder $\mathrm{R}$. Influence of $\mathrm{Fe}, \mathrm{Cr}$ and $\mathrm{Al}$ on hydrogen incorporation in orthopyroxene. Eur J Mineral, 2004, 16: 703-711

39 Kohn S C, Roome B M, Smith M E, et al. Testing a potential mantle geohygrometer: The effect of dissolved water on the intracrystalline partitioning of $\mathrm{Al}$ in orthopyroxene. Earth Planet Sci Lett, 2005, 238: 342-350

40 Lu R, Keppler H. Water solubility in pyrope to 100 kbar. Contrib Mineral Petrol, 1997, 129: 35-42

41 Pitzer K S, Sterner S M. Equations of state valid continuously from zero to extreme pressures for $\mathrm{H}_{2} \mathrm{O}$ and $\mathrm{CO}_{2}$. J Chem Phys, 1994, 101: 3111-3116

42 Rudnick R L, McDonough W F, O'Connell R J. Thermal structure, thickness and composition of continental lithosphere. Chem Geol, 1998, 145: 395-411

43 Turcotte D L, Schubert G. Geodynamics. Cambridge: Cambridge University Press, 2002. 1-450

44 Katsura T, Yoneda A, Yamazaki D, et al. Adiabatic temperature profile in the mantle. Phys Earth Planet Inter, 2010, 183: 212-218

45 Hirschmann M M, Aubaud C, Withers A C. Storage capacity of $\mathrm{H}_{2} \mathrm{O}$ in nominally anhydrous minerals in the upper mantle. Earth Planet Sci Lett, 2005, 236: 167-181

46 Evans R L, Hirth G, Baba K, et al. Geophysical evidence from the MELT area for compositional controls on oceanic plates. Nature, 2005, 437: 249-252

Open Access This article is distributed under the terms of the Creative Commons Attribution License which permits any use, distribution, and reproduction in any medium, provided the original author(s) and source are credited. 